\title{
The next 'killer ap' has been here all along: case studies as practical business applications
}

\author{
William M. Shanahan \\ Shanahan Marketing Communications \\ Chicago, USA \\ E-mail: bill@shanahan.com \\ International School of Management \\ 148, rue de Grenelle, Paris, 75007 France
}

\begin{abstract}
The next 'killer ap' is a term the software development community uses to describe its great quest for advancing technology by defining and meeting users' needs and wants and rapidly diffusing it throughout the market. By making a computer application (program) that meets those needs and making it is so ubiquitously available, it creates a flood of demand. Business managers are also questing after killer aps, but of another kind. These aps are neither confined to computers nor necessarily for new product development; they are for aiding the firm with detecting problems and finding solutions. The quest may seem quixotic, unless managers remember earlier ways of discovery and learning. We bring in the business case study.
\end{abstract}

Keywords: case study; case history; cases; killer ap; problem; solution; investigation; analysis; decision making.

Reference to this paper should be made as follows: Shanahan, W.M. (2004) 'The next 'killer ap' has been here all along: case studies as practical business applications', Int. J. Management and Decision Making, Vol. 5, No. 4, pp.392-402.

Biographical notes: Bill Shanahan, DBA, is President of Shanahan Marketing Communications, a full-service marketing, advertising, and public relations firm in Chicago. Over his career, Bill has worked on both B2B and consumer products for major US and international brands, such as Chicago Board Options Exchange; Kraft, Philip Morris; Sears; Siemens-ITE Electrical and Electronics; and the Government of Greece to name a few. He is experienced in many marketing areas beyond his specialty in communications. Dr. Shanahan has taught design at the International Academy of Design and Technology, eMarketing Communications at Illinois Institute of Technology, Marketing at the International School of Management (ISM), Paris, and Consumer Behavior at ISEG, Paris. Also, he is a prime architect of a University of Chicago eBusiness Certificate Program for which he taught components and wrote a case study. Dr. Shanahan has guest lectured to students of the University of Notre Dame, Roosevelt University, and the University of Management and Marketing, Warsaw, Poland. He holds a Doctorate of Business Administration (D.B.A.) degree in International Business Management from ISM, Paris. 


\section{Introduction}

A very common strategy in software development businesses revolves around the search for the next 'killer ap' (application). In the tech world, it means a single purpose (Segaller, 1998), which will cause the acceptance of a new or advanced technology. Usually this means a desktop computer program that is made available to anyone, like page make-up applications/programs and word processors that developed in the past. In the domain of business management, the 'killer ap' can be thought of as an application of resources: personnel, process, or capital, which will allow for the strengthening, the advancement, or the acceptance of a firm's service or product. The business management tool, the killer ap, referred to here that meets parallel criteria is the case study.

Sometimes managers at the top forget not the principles of management they learned in business school, but how they learned them. Case studies need to jump a great divide. Some thinking goes that what happens in schools is not applicable to the everyday running of business. Things like case studies are often viewed as training wheels for business students. However, there are solid opportunities for using case studies in real business environments. The desire to use them may have more to do with just how closely management actually wants to look, or more than look, see. A corporate look in the mirror may seem scary, but without doing so, it is difficult to see what parts need extra work to get into shape. Besides the reflection aspect of doing a case study, a case study project also helps to destroy silos and build esprit de corps by uniting groups in a common cause ... that of making the firm healthier.

The business case method of teaching is deeply engrained in schools around the world. For example, cases are used at the University of Hong Kong School of Business and Melbourne Business School in the Pacific region. Harvard University made it a solid direction in teaching in the USA starting in 1924, and over the years it has spread around the country as a basic tool. One also finds the case method of teaching is ubiquitous in European business schools from Denmark to Slovenia, France, Ireland, the UK, Spain, Germany, and beyond (ECCH, 2004).

\section{When a case is not a case}

In the USA, Harvard-style case studies are used extensively in master's degree programmes. Those fortunate enough to be exposed to this fine teaching method to some degree typically will continue in pursuit of like readings throughout their careers. An excellent post-graduate source for such is Harvard Business Review (HBR), which monthly poses a new case that can cover any of many business disciplines. The major difference between the in-class Harvard case studies and HBR studies is the depth of information provided. The depth in HBR cases is often throttled by publishing parameters. Harvard Business Review's monthly cases are typically written to appeal to a broader audience than the targeted in-class versions. Harvard Business Review's cases must pique and retain the interest of their reader/subscription base. Within this profit generating enterprise, they also need to meet certain publication layout requirements, such as space allocation. Therefore, the HBR versions often do not include the financial intricacies that in-class versions do, and instead focus on situational problems and solutions. These HBR cases are sometimes extrapolated into class versions, as is, or with added information. 
When hopping from website to website while doing online research, it is very common to find that a site has a topic listed as 'cases'. However, when reviewing these more closely, one quickly finds 'case' to be a highly misappropriated term for what these writings really are. They are corporate self-encomiums, propaganda, something a bit more than public relations releases.

These writings referred to as 'cases' often have no real point in them. They do not show any real historical perspective, as they are usually written in the present tense, or very near past. They usually exist to promote what clients/customers the host site's owner currently serves, which they believe is enticement to that corporation's prospects. These 'cases' also do not offer much thought stimulation encouraging their readers to understand how insightful the site-owner corporation is, or might be. And, they usually have little depth, as going too deep would likely expose them to confidentiality conflicts. They often read more as an abstract would, rather than a case. The take-away from these seems to follow a threadbare formula: here is what we did, here is for whom we did it, and are we not great.

\subsection{Differentiating a case history from a case study}

Rogers (1978) clearly points out to look upon cases from three specific perspectives: case history, case study, and case project. At this time, we will not discuss case projects, which are used in testing situations by professional associations. Later a scheme for developing the case project as the 'killer ap' is suggested. In simplest terms, Rogers defines the differences among these three. Case histories may or may not be set in an environment. They usually follow a chronological, methodical order, presenting all the evidentiary information one can muster. The major differentiator for case histories is that they are conclusive.

Case studies mostly differ from case histories in that the narratives are purposely fractured or left open ended, so as to allow the reader entry. They are written in an invitational way so as to draw the reader in and cause him/her to want to participate. Therefore, Rogers (1978) states,

"The problems are not always highlighted, or even made clear; they emerge as the case material is subjected to analysis. A conclusion is not necessarily reached nor is the point arrived at necessarily irreversible."

When they are brought to a conclusion, it is usually to point up a disastrous outcome but allows for a pathway or two in the middle that could have been taken to produce a positive outcome.

However, in the event of no conclusion to a case, as a learning/training aid, it must always have a focus. Cases must not be endless wanderings. The author must have an end in mind that the reader is expected to discover as part of an investigation and analysis. The Harvard Business Review cases are normally left open ended allowing the reader to ponder the proposition or situation. But, the case study is always followed up with analyses and conclusions drawn by three experts in the field for the subject at hand. Sometimes the answers from the three are quite divergent, but each provides a logical outcome. Other times the answers seem obvious and are synchronised across the entire review board.

Two of many other definitions of 'case study' that very much support Rogers can be found at the University of Bradford website (Peace, 2003). 
- A case study is an empirical inquiry that:

- investigates a contemporary phenomenon within its real-life context; when

- the boundaries between phenomenon and context are not clearly evident; and in which

- $\quad$ multiple sources of evidence are used (Yin, 1989).

- A case study is:

- a detailed examination of an event (or a series of related events) which the analyst believes exhibits (or exhibit) the operation of some identified general theoretical principle (Mitchel, 1983).

\subsection{Professional disciplines using cases}

In legal cases, all relevant information about participants is investigated, analysed, and presented. These cases are so well understood in the legal community that they are simply cited by party names (Roe v. Wade) while positioning a prosecution or defence. They are case histories in that respect. But law schools also commonly tell their students to dismiss the conclusions drawn by a judge and learn to argue both sides of the case. In this usage they are case studies.

A post-mortem review at a teaching hospital in which step-by-step analysis and reporting are presented by an attending physician to a board of review is an example of case history. However, with some medical training techniques, such as problem-based learning (PBL), case studies are developed, as PBL is active, collaborative with small groups, it is open ended, it requires investigation across several disciplines, and it calls for analysis within a clinical context.

Many other professions also use case histories and case studies as learning/training tools. These include engineering, design, architecture, psychiatry, and social work to name several.

\subsection{Business cases}

All cases whether historical reports, suppositions, or testing vehicles have at least two things in common: investigation and analysis. The case can be, and should be, as intriguing as an old-fashioned Sherlock Holmes tale. When Arthur Conan Doyle developed Sherlock, he used techniques very similar to what we would want to incorporate into a business case study today.

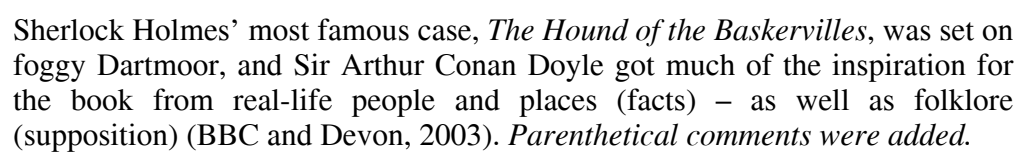

With this approach, all along the way one is drawn into twists and turns in plots and subplots that lead the book reader or movie watcher to draw conclusions. Sometimes, the likes of Doyle, or Alfred Hitchcock with film (Badger, 2003), would place obstacles and clues along the way so that we could analyse and formulate logical outcomes. Sometimes, we feel misled by a McGuffin placed before us. But that is also what makes it beguiling; keeping us involved. Likewise, in business case studies, all the clues should 
be presented. Mental teasing to stimulate deeper analysis can be provided, but the conclusion must be veiled.

The case study method is a process for determining problems and causation in hypothetical or real situations. It is a research aggregation approach, sometimes using primary research, but mostly secondary research of both the quantitative and qualitative kind. When a problem arises within a firm, there may seem to be many ways to go about solving it temporarily, but without getting at the root cause, it is likely to return. As might be done with medical triage, these problems should be considered along the continuum of acute, chronic, and preventive.

The case study method may or may not be usable for solving acute problems, quite often not. Acute problems need to be acted upon immediately, and case studies, as that label indicates, call for time to do them properly. A study is an intensive analysis (Merriam-Webster, 2003) done over time with care. They should not be knee-jerk reactions. However, an emergency room triage procedure may be employed. That is, attend to the most threatening condition first allowing ancillary conditions to persist. This well-accepted medical practice is a delaying tactic, which allows time for a comprehensive and proper diagnosis to develop.

\section{It's on-the-job training for the educated}

When it comes to case studies, there is an added dimension within firms that is rarely discussed: Building esprit de corp. Company case studies should not be done by just one individual working in a vacuum. Several small groups of two to three people within a speciality can work synergistically. A case study that needs developing calls for involving management on all levels and all departments involved. Business problems are often of a systemic nature. By this, I do not mean system wide, I mean for example, the problem may be in finance, but the cause is in shipping. By having all ranks of management involved, it is most likely that the problem can be traced. The process may also lead to other preventive measures as the prime problem unfolds before all participants. There are more minds to help solve the puzzle and avoid future traps.

But where to start seems to be one of the more daunting tasks. Start the case study without enough foundation information and all evolving theory could fall short of the desired task. Enter too soon and one may get bogged down. A plan, a framework, needs to be utilised to develop a good departure point. When an individual is doing the case study development, s/he will have to follow a linear flow just to manage the project. However, in group situations, once the subject to be studied has been identified and the management team has accepted the approach of a case study, a team leader, an implementer, for this project needs to be appointed by upper management. The most likely candidate will be the instigator of the case study. Then, two to three person teams should each be assigned very specific tasks by the team implementer. Working the teams in parallel rather than in linear form is what allows the case study to move at greatest possible speed, helps prevent too much 'group-think', ${ }^{1}$ and keeps up the thrill of the hunt.

Once the teams are identified, the next step should be about numbers, as they are quantifiable. When presenting only the bottom line information, not the process of determination, conditions should be easy for all to understand when properly presented by each specialist group. The operations team should worry about production capacity, inventory, and logistics criteria. The finance team should dig into aspects such as cash 
flow, NPV projections, and even options if appropriate. The marketing team should analyse pricing, distribution, promotion expectations and expenditures. These will all yield invaluable information that can be meshed with the other groups into a meta-analysis.

If the numbers, money in particular, are what provide nutrition to the place, then its people are the lifeblood of the organisation. The corporate corpus is just as organic as an individual's. Peaks and valleys in demand cause the employees' pace to act like tensor and contractor muscles. The whole of the work force has a growth spurt in boom times, and recessions cause atrophy in the ranks. Using case studies to identify what is draining a firm's health should keep a firm from gangrenous conditions as it cauterises bleeders and closes personnel wounds.

So, this is where the in-house case project and remembrances of business school case studies come into play for the top executives. After the numbers, people issues should be investigated. People in teams and people as individuals are to be considered. All employees are interactive and have constantly changing relationships with each other and the firm, its products, and the firm's constituents. It's the employees' daily processes and tools that allow them to fully function and produce. These relationships, their duties, and their physical environment must all be explored. Qualitative techniques such as interviews and focus groups can be used with the personnel to get at root causes and effects, at least as perceived by the people.

It is not suggested here that upper management actually conduct the focus groups and the like, but they should direct those that do the conducting. Management needs to get involved in the process in appropriate ways. They need to take on the extra burden of the case project management in order to resolve the problems they are pursuing. Those problems may be apparent from their perspective, but not from lower echelons. It is a rarefied view to say the least. That is what is sometimes lacking. Issuing an edict for a case project, but staying uninvolved, serves no purpose.

The quantifiable numbers and qualified statements from the people then lead to the nexus of conjectural analysis. Here, as all available information is analysed, logical assumptions can be made. This is not unlike Sherlock reviewing the evidence before him and then supposing what events might be taking place. This might be 'elementary' for himself and Dr. Watson, but not so for a corporation with real-world problems. This analysis must be played back and forth among the groups until the hidden clues are all deciphered. Once the unknown is known, the problem can be identified for all, but most likely with some resistance, especially from the people responsible for the cause of the problem. However, all must go into this process with the 'systemic problem' understanding mentioned earlier. This should not be a hunt for who is at fault, but a hunt for a solution to the problem.

The problem can come in many forms: people, production capabilities and facilities, cash flow, management, structure, etc. All of these have decision making in common. All decisions are bifurcated by quality and acceptance. Finding the best balance between these two branches is what is needed. Rogers (1978) models acceptance of a decision on the basis of those who will be affected by the decision. He uses a simple and highly effective demonstration on how to choose the best balance. First he leads one down a comfortable path that would have an expected outcome of ' $\mathrm{B}$ ' being the most effective balance based on the table that follows, as that is the 'highest combined' score: 


\begin{tabular}{llllllll}
\hline Quality & (most preferred) & A & $B$ & C & D & E & (least preferred) \\
Acceptance & (most preferred) & D & $B$ & C & A & E & (least preferred) \\
\hline
\end{tabular}

Then he notes that the correct formula to use is: Effective decision $=$ quality $\times$ acceptance

Rogers discounts the B-B highest combined score as being the best choice, as this is qualitative information and the B-B outcome does not indicate a rigorous determination of a more probable outcome. What he suggests is having experienced personnel rank each of the two dimensions. Then using averages, weight the letter forms and multiply each increment of the respondents' preferred rank in the first dimension by the increment of the respondents' preferred rank of the other dimension. That is, in a weighted situation as described here and shown in the Table 1 that follows, we see that the A-D combination scores higher than the B-B combination.

Table 1 Quality of Decision X Acceptance of Decision

\begin{tabular}{rrrrrrrrrr}
\hline $\mathrm{A}$ & $35 \%$ & $\times$ & $\mathrm{D}$ & $16 \%$ & $\mathrm{~A}$ & $\times$ & $\mathrm{D}$ & $=$ & 560 \\
$\mathrm{~B}$ & $23 \%$ & $\times$ & $\mathrm{B}$ & $23 \%$ & $\mathrm{~B}$ & $\times$ & $\mathrm{B}$ & $=$ & 529 \\
$\mathrm{C}$ & $17 \%$ & $\times$ & $\mathrm{C}$ & $17 \%$ & $\mathrm{C}$ & $\times$ & $\mathrm{C}$ & $=$ & 289 \\
$\mathrm{D}$ & $16 \%$ & $\times$ & $\mathrm{A}$ & $35 \%$ & $\mathrm{D}$ & $\times$ & $\mathrm{A}$ & $=$ & 560 \\
$\mathrm{E}$ & $9 \%$ & $\times$ & $\mathrm{E}$ & $9 \%$ & $\mathrm{E}$ & $\times$ & $\mathrm{E}$ & $=$ & 81 \\
\hline
\end{tabular}

Rogers goes on to explain that the experienced personnel doing the weighting in a real situation would be specialists in each investigation group who already have solid knowledge and judgment in their subject areas. This process is dependent on executives making objective assessments. Because the weighting is subjective, albeit sound, it is fiddle factoring. What is interesting here is that the acceptance fork deals with the human condition, which is normally left out of case studies. Cases tend to be a bit distant from people, as their variability is so broad. Personality traits are normally only sketched in often setting up stereotypes in the reader's mind. But the human factor of acceptance cannot be overlooked when discussing effective decisions.

A best practice for business management calls for objectives to be determined, stated in writing, agreement reached by all parties involved with sign-off, and then tactics implemented to meet the objectives. This holds true for in-company business case projects as well. The results of the case study for academic purposes are divergent from the results for a business situational project, which yield definite outcomes over time.

\section{Suggestions for starting}

Following is a chart and table offering a place from which to start a business case study. There is nothing absolute about the suggestion, but there is a logic and flow that should make the process easier for all to follow. The first step, which should keep the project from becoming unwieldy, is to divide the firm's areas of responsibilities by some equal means and then pinpoint where the problem is apparent. As mentioned earlier, the arena that is identified as having the problem exposed is not necessarily the arena that is causing the problem. In the example here, a chart of intersecting arenas is used. They intersect because all departments and functions have some overlap. But using the arenas 
is a quick way to organise the project. Once the problem location is pinpointed, the investigation will be able to radiate from there. Other titles, organisations, and methods for visualising the problem, such as a $2 \times 2$ matrix, may also be used.

Figure 1 Four major arenas for possible investigation

\section{Arena examples:}

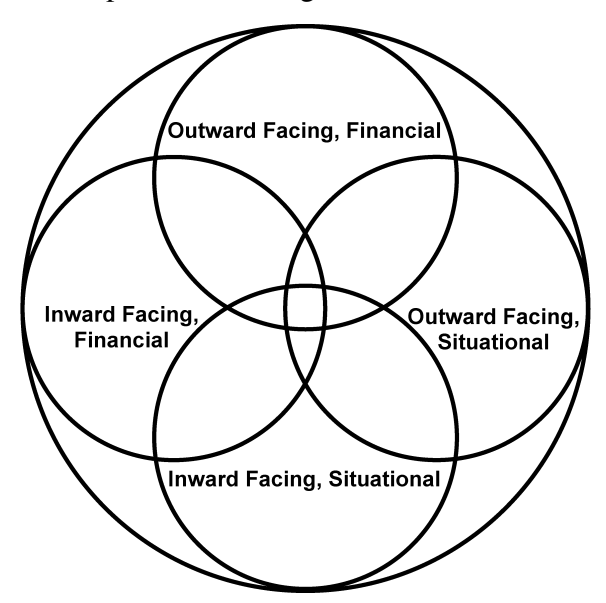

Outward facing, financial. This arena is under the guise of marketing through its pricing structure. If customers are not buying because of price, the first inclination might be that marketing has a miscalculation or the product is not positioned correctly, that is if it were positioned as a premium brand, the price would be acceptable to the consumer. But, neither of those may be true. Corporate expansion may be putting greater pressure on the per unit costs than what competition has to bear.

Outward facing, situational. This too may be under marketing's watchful eye with management believing a product is not being promoted properly to sales personnel at retailers. Management wants to up SPIFFS ${ }^{2}$ to entice the sales people to sell more on the firm's behalf. But, an investigation by marketing could show that word-of-mouth is damaging the product's reputation. Due to a new manufacturing technique, the product is now perceived as unreliable.

Inward facing, financial. There is a sudden bleed in the cash flow, but why. Eyes are cast to marketing again, but this time it is the sales personnel. As it turns out, its year end number crunching and the leading salesman is way out in front again this year.

He told buyers they should buy before a price increase next year and if they doubled their current order they could just extend their payment terms a few weeks, and no one would notice.

Inward facing, situational. In fourteen years of operating the current plant, the long-time general manager always had smooth relations with the labour force. Not long ago he began to notice that employees seemed disgruntled, but they would not talk about it. $\mathrm{He}$ figured it was fear of losing their jobs due to automation plans that were revealed two months earlier. What he was overlooking was the supervisor he appointed also two months earlier.

Once the arenas, or equivalent, are drawn, then draft a flow chart for all to know who or what department is responsible for each arena. The case must not seem like a mere exercise. There is a definite point to it and that needs to be made clear. In referencing three fine sources and writing guidelines for teaching with cases, The Schreyer Institute establishes two significant points that carry over well to the business environment: " 1 , a case should appear authentic and realistic, and 2, a case should not propound theories, but 
rather pose complex, controversial issues" (Schreyer Institute for Innovation in Learning, 2004). The word 'controversial' should not be intimidating, as here controversy is a positive condition. Cases tend to show even the warts on the portrait of the firm, unmasking political positions with much being discerned.

Here is a suggested flow to prepare forms for use by all participants:

- $\quad$ Simple description block. Project name, date, division, product involved.

- Product description. One or two paragraphs.

- Signature block. Names and titles of participants and of authorising management.

- Executive summary. Allow room for this to be plugged in at the end. Highlight the SWOT analysis.

- Financial perspective. Three year review of key financial data.

- Problem description. Simplest summary of situation.

- $\quad$ Product history. Successes and failures.

- Chronology of the case study events. Simple date and single line descriptions.

- SWOT analysis. Keep each point to a paragraph or two if possible.

- Case study project plan. Note areas of responsibility, participants, budget, due dates, contingency plans.

- $\quad$ Prepare financial projections. P\&L, cash flow, balance sheets.

- Lost opportunities. Risks involved in acting or not acting and the impact those losses could have.

- Final recommendations. This is the time to elaborate on all findings in detail.

\section{Replication of case experience}

Response and control are the two drivers that will be taken with the identified problem(s). The drivers may be triggered due to internal pressures such as outdated equipment or external pressures such as a new taxing body or tariffs. As mentioned earlier, it is a mistake for a company to knee-jerk react. Ideally, they can head off problems before they begin by being proactive while using case studies as a preventative.

Based on the results from the study, functional plans for "purchasing, human resources, research and development, marketing, sales, servicing, finance and profit" (Rogers, 1978) can all be well thought out. Objectives for each function can be defined and tactics determined to allow for implementation. Budgets, including cash flows, NPV projection, and expected return on investment can also be established. It should also be remembered that other discoveries will be made on the way to meeting the goal. In a 2003 paper in the European case clearing house newsletter, Roger Schmenner of IMD (International Institute for Management Development, Switzerland) notes a high value of the case method when he states, 


\begin{abstract}
"Although it is the decision in the case and its analysis that are most important to me, cases can be great ways to learn about the subtleties of business - company culture, relationships among people, relationships with unions, international issues." (Schmenner, 2003)
\end{abstract}

That holds true in the business management venue, as well as the business school management classroom.

Once the business case study has prompted changes and advancements, the results should then be compiled into a report. When the results are merged with the initial project, the case will then move from the case study phase to the case history phase. From this case history, the firm can then extract another open-ended case study that parallels the original situation in structure.

That case study extract would become a valuable tool for the company, as it would be used as a plot for future studies. The process self-propagates with multiple generations of reports that can be used for modelling solutions. The primary reason for the extraction is that in a business situation, unlike the psychiatric world or social sciences world (Peace, 2003), the company would not want future players to replicate exactly what has happened historically, but rather would want a new investigation into new problems. The results of the newly extracted case study would soon become the company's newest 'how to' guide for future problem solving and prevention. A recommendation is to have the most senior manager involved in the original study take on this task directly, or at minimum oversee it, so that there might be continuity of thought from the benchmark to the extracted new mission case study.

\title{
References
}

Badger, S. (2003) A Guide to Alfred Hitchcock's Best Lesser Known Films, retrieved November 17, http://www.suspense-movies.com/directors/alfred-hitchcock (website).

BBC, Devon (2003) 100 Years of Hound of the Baskervilles, retrieved December 16, http:// classiclit.about.com/gi/dynamic/offsite.htm?site=http\%3A\%2F\%2Fwww.bbc.co.uk\%2Fdevon \%2Foutdoors\%2Fmoors\%2Fhound_baskervilles.shtml (website).

ECCH (2004) Materials on the Case Method, Retrieved January 16, 2004, European Case Clearing House, http://www.ecch.cranfield.ac.uk/america/pages/obtain/casemats.html (website).

Merriam-Webster (2003) Definition: 'Case Study', retrieved November 19, http:// www.m-w.com/cgi-bin/dictionary?book=Dictionary\&va=study (website).

Mitchel, J.C. (1983) 'Case and situation analysis', Sociological Review, Vol. 31, No. 2, pp.187-211.

Peace (2003) Peace Studies Online. University of Bradford, retrieved December 19, http://www.peacestudiesonline.org/docs/Case\%20Studies.DOC (website), West Yorkshire, UK.

Rogers, L. (1978) Business Analysis for Marketing Managers, Heinemann Publishing Book, UK.

Schmenner, R. (2003) 'Thoughts on case teaching in management education', ECCHO, The newsletter of the European Case Clearing House, Summer, No. 30.

Schreyer Institute for Innovation in Learning (2004) Guidelines for Case Writing, Retrieved January 17, http://www.inov8.psu.edu/toolbox/CaseGuidelines.PDF (PDF document).

Segaller, L. (1998)_Nerds 2.0.1: a brief history of the Internet, TV Books, L.L.C. Book, NY, p.383.

Wikipedia (2004) Topic: Group Think, retrieved January 12, http://en.wikipedia.org/wiki/ Groupthink (website).

Yin, R.K. (1989) Case Study Research: Design and Methods, Revised edition, Book, Sage. 


\section{Notes}

'In 1972 Irving Janis, a psychologist, coined the phrase 'group-think' as a way of expressing peoples' desires for conformity of thought and acceptance when they are in a crowd. If an individual allows his or her desire for acceptance by a crowd to overshadow his or her true individual opinion, then that is group-think (Wikipedia, 2004).

${ }^{2}$ SPIFFS is an acronym for Sales Promotion Incentives For Floor Sales. It is often spelled in initial caps or all lower case, as it has become common usage for the concept of incentivizing retail sales personnel. In Advertising, Promotion, \& Supplemental Aspects of Integrated Marketing Communications, $\sigma^{\text {th }} E d$., p.513, author, Terrance A. Shimp states, "Manufacturers... provide financial incentives to retail salespeople to aggressively sell to consumers... This practice is called push money, or spiffs." The concept and term has been extended to B2B situations where the sales personnel at a distributor sometimes may earn a per-sale incentive direct from a manufacturer. 